\title{
Correlates of Depressive Symptoms among Middle-Aged and Older Homeless Adults Using the 9-Item Patient Health Questionnaire
}

\author{
Lin-Yun Wang ${ }^{1}$, Lan-Ping Lin ${ }^{2}$, Yun-Cheng Chen ${ }^{3}$, Tai-Wen Wang ${ }^{3}$ and Jin-Ding Lin ${ }^{4, *}$ \\ 1 Department of Family Studies and Child Development, Shih Chien University, Taipei 104, Taiwan; \\ nose.123@yahoo.com.tw \\ 2 Department of Senior Citizen Care and Welfare, Ching Kuo Institute of Management and Health, \\ Keelung 203, Taiwan; lanping518@gmail.com \\ 3 School of Public Health, National Defense Medical Center, Taipei 144, Taiwan; \\ 607810031@mail.ndmctsgh.edu.tw (Y.-C.C.); s8038129@gmail.com (T.-W.W.) \\ 4 Institute of Long-Term Care, Mackay Medical College, New Taipei City 252, Taiwan \\ * Correspondence: jack.lin4691@mmc.edu.tw; Tel.: +886-2-2636-0303-1816
}

Received: 21 June 2020; Accepted: 30 June 2020; Published: 2 July 2020

\begin{abstract}
This study investigates the screening for depressive symptoms among middle-aged and older homeless adults based on Patient Health Questionnaire-9 (PHQ-9) and examines the possible factors associated with their major depressive symptoms. A cross-sectional survey was employed, and research subjects included 129 homeless people aged 45 years old and over in Taipei Wanhua District and Taipei Main Station. We used a structured questionnaire and face-to-face interview conducted by three social workers to collect data in the analyses. The content of the questionnaire included an informed consent form, demographic characteristics, enabling and need factors of healthcare, and PHQ-9 of homeless people. Results revealed that $15.5 \%$ respondents were free of depressive symptoms, $16.3 \%$ had mild level (score 5-9), 31.8\% had moderate level (score 10-14), 26.4\% had moderately severe level (score 15-19), and 10.1\% had severe level of depressive symptoms (score 20-27). Adopting a PHQ-9 score 10 as a cut-off point for major depressive symptoms, $68.3 \%$ of middle-aged and older homeless adults were the cases needing to be referred to healthcare settings for further recheck in the near future. A multiple regression analysis found gender, age, and usage of psychiatric outpatient care were associated with major depressive symptom occurrence. The female participants were less likely to have major depressive symptoms than the male participants ( $O R=0.29$, $95 \% \mathrm{CI}=0.09-0.96)$. The elderly participants were more likely to have major depressive symptoms than the aged $45-54$ years $(\mathrm{OR}=5.29,95 \% \mathrm{CI}=1.44-19.41)$. Those participants who have ever used psychiatric outpatient care were significantly more correlated with the occurrence of major depressive symptoms than their counterparts ( $\mathrm{OR}=3.65,95 \% \mathrm{CI}=1.46-9.09)$. The present study suggests that in the future health policy should eliminate the risk factors of depressive symptoms and improve mental healthcare access, to improve the health and wellbeing of the homeless population.
\end{abstract}

Keywords: homeless population; depression; mental health; Patient Health Questionnaire-9 (PHQ-9)

\section{Introduction}

Homelessness is a serious public health problem driven by social and economic inequality [1], and patients present increasingly complex physical and mental health conditions [2]. Homeless adults were found to have high rates of functional vision diseases, dermatological/hand-foot problems, and tuberculosis prevalence [3]. Hospitalizations among homeless persons are rising [4], and there are significant disparities in in-hospital care and mortality between homeless and non-homeless adults 
with cardiovascular conditions [5]. The overall healthcare costs for homeless patients were substantial; therefore, it is necessary to treat homelessness as a merge health and social issue to improve the health outcomes of people experiencing homelessness [6].

Individuals who are homeless perceived experiences as negative and unequal in access and use of mainstream primary healthcare services [7]. Low healthcare services utilization and affordability is an issue among the homeless population [8]. Although previous literature provides suggestions on policy and programs to improve the health of homeless individuals, healthcare providers should also need to address influencing factors for homelessness [9]. A South Korean study indicated that service disparities in homeless people exist in terms of the main place to stay, health, and gender and the current homeless support system [10]. In general, homeless adults experienced more unmet healthcare needs than the general population, and policies to eliminate the disparities and barriers of primary care access in these people are needed [11].

The homeless adults tended to have very high burdens of mental health and substance use disorders [12,13]. They were more likely to present, late in their illness and treatment, low utilization of primary care and outpatient services; have high rate of emergency and hospitalization, and poor compliance with medication, and there were less of them in psychiatric services [14]. Those homeless people received a formal diagnosis of mental health conditions, mainly including depression, addiction disorder, anxiety, schizophrenia, and bipolar disorder [15]. According to a previous study, there were $30-50 \%$ of homeless people who have a significant mental illness; most prevalent illnesses included functional psychoses, acute distress, and personality dysfunction. Co-morbidity of mental illness and substance abuse occurred in $20 \%$, and they also had a higher rate of physical morbidity than the general population [16].

The homeless population is aging, and nearly half of older homeless adults in a population-based cohort became homeless for the first time after age 50 in New York [17,18]. In Ontario, Canada, almost 70 percent of older homeless people reported first becoming homeless between the ages of 41 and 60 [19]. Homeless adults aged 50 and older have unique health problems compared to younger homeless adults [20,21]; the aging trends suggest that chronic conditions will become increasingly prominent for homeless health services [22]. Therefore, there has been a growing focus on the issues of developing strategies to meet the health needs [23] and prevent and end homelessness among older adults $[18,24]$.

There is a strong public stigmatization of homeless people in Taiwan; one previous study indicated that the homeless are not a homogeneous social group but are going through a similar trajectory of street life [25]. The causes of homelessness in Taiwan are somewhat different to those in other developed countries. Typically, a homeless person in Taiwan becomes so through a series of events beyond his control or due to poor decisions that had unforeseen circumstances, such events as unexpected ill-health, loss of his identity card, irreconcilable family conflict, being trapped in some addiction or battling mental challenges, etc. [26]. In Taipei, not everyone had become aware of the homeless issue, due to low housing and basic living coverage and public services, and also there is an inadequate number of social workers responsible for homeless welfare services in the Taipei City Government [27]. To improve homeless services, initiatives such as a universal principle for nationwide homeless delivery systems, employment consultation, and housing compensation, supportive relationships with the mainstream are required [28].

Actions to prevent and respond to homelessness by addressing the mental health problems across the life course are essential [29]. There is a need for public health and social policy efforts to support and care for homeless persons to reduce disparities in healthcare and improve health outcomes for this population and to prevent the elderly people who are at-risk from becoming homeless. Homeless individuals with differing life experiences of different ages may have different needs and strengths and thus need different services and interventions [18]. About one-half of both the chronic and newly homeless aged 50 and older adults have possible or probable depression [19]. As the aging population growing in Taiwan, the middle and older aged people need to pay much attention to 
the onset of homelessness and the consequent health needs. Especially, there is a significant focus on the mental health of vulnerable populations, but little is known about the profile and correlates of depressive symptoms among homeless persons, particularly in middle-aged and older homeless adults. Therefore, the present study investigates the screening of depressive symptoms based on the Patient Health Questionnaire-9 (PHQ-9) and examines the possible factors associated with their major depressive symptoms.

\section{Methods}

The homeless refers to people who often stay in public places or places where the public can enter, and there were 647 registered homeless people located in Taipei City, Taiwan, according to the official report [30]. In Taipei City, Wanhua District and Taipei Main Station had a higher population of homeless people than other areas. These two areas attract large numbers of homeless people because of the old town history and geographic location in the center of Taipei City. This study employed a cross-sectional survey to recruit homeless people aged 45 years old and over in Taipei Wanhua District and Taipei Main Station, where the study population $(\mathrm{N}=292)$ come from the homeless registries of Wanhua District Welfare Center $(n=252)$ and Homeless Taiwan $(n=40)$.

Regarding the research ethical considerations, firstly, the Wanhua District Welfare Center and Homeless Taiwan agreed to participate in this study after their official review of the research proposal. It meant the researcher could plan to interview the homeless adults who registered in their service system. Secondly, the researcher introduced the study purposes and right protections to the participant and then they signed informed consent forms. We emphasized that the study was only for academic research and analysis. It was anonymous and the information was strictly confidential, and the questionnaire content or process were not to be disclosed to the public. In the process of filling out the questionnaire, if the participant felt uncomfortable or did not want to answer, they could ask to withdraw freely from this study at any time. Finally, those people who completed the answers to the entire questionnaire received a NT $\$ 100$ cash coupon for the convenience store in appreciation of their support.

A structured questionnaire was used and face to face interview conducted by three social workers to collect the data in these two areas-offices of Wanhua District Welfare Center and Homeless Taiwan. Those homeless adults who are literate, communicated in Mandarin or Taiwanese language and could express their needs clearly were included in this study. The interview time was $30 \mathrm{~min}$ to $1 \mathrm{~h}$. The content of the Chinese questionnaire included demographic characteristics, enabling (social economic status, living location, medical care setting) and need (health behaviors and health status) factors of healthcare, and depressive symptoms (PHQ-9) of homeless people. The expert surface validity was conducted to improve the readability, consistency, and formatting of the questionnaire. The statistical reliability of the PHQ-9 instrument was assessed using Cronbach alpha with the data collected in this study, and the value was 0.865 .

The PHQ-9 is a nine-question instrument originally given to patients in a primary care setting to screen for the presence and severity of depression; it is widely adopted to test mental health wellbeing [31-33] and is suitable for use for patients of various cultural backgrounds [34-42]. In the general Chinese population, the Chinese version of the PHQ-9 is a valid tool with good reliability for screening depression [43-45], and it is widely used in the populations of China, Hong Kong, and Taiwan [46-48]. The items of PHQ-9 are the following: Q1: Little interest or pleasure in doing things? Q2: Feeling down, depressed, or hopeless? Q3: Trouble falling or staying asleep or sleeping too much? Q4: Feeling tired or having little energy? Q5: Poor appetite or overeating? Q6: Feeling bad about yourself - or that you are a failure or have let yourself or your family down? Q7: Trouble concentrating on things, such as reading the newspaper or watching television? Q8: Moving or speaking so slowly that other people could have noticed? Or so fidgety or restless that you have been moving a lot more than usual? Q9: Thoughts that you would be better off dead or thoughts of hurting yourself in some way? As a screening tool for depressive symptoms, the PHQ-9 scores each of the 
criteria on a scale from " 0 " (not at all) to " 3 " (nearly every day), with summed scores ranging from 0 (free of depressive symptoms) to 27 (all symptoms occurring daily). The cut-off points of 5, 10, 15, and 20 represent mild, moderate, moderately severe, and severe depression, respectively [49].

A convenience sampling that recruited data from 129 valid respondents was analyzed by SPSS version 18.0 in this study. Firstly, descriptive analyses were conducted to present data of participant's characteristics in demographic, enabling and need conditions and their PHQ-9 scores. Secondly, univariate chi-square analyses between depressive symptom scores and the participant's characteristics were described. Finally, multiple logistic regression models were conducted to identify the associated factors of major depressive symptoms of the participants.

\section{Results}

\subsection{Demographic, Enabling, and Need Characteristics of Homeless Adults}

Table 1 shows the demographic data of the homeless adults: 52.7\% subjects were from Taipei City, $21.8 \%$ were from new Taipei City, and 15.4\% were from other cities. Most of the subjects were male $(88.4 \%)$, and their average age was 58.3 years. More than $50 \%$ of the participants finished junior high school education or less, $51.2 \%$ of the subjects were single and $36.4 \%$ were divorced. In terms of their current living locations, $41.1 \%$ were often located in public parks, $28.7 \%$ were in the homeless shelters, and $14 \%$ were in train/bus station surroundings. Subjects who experienced less than one year in a homeless condition made up $27.9 \%$ of the study population, $41.1 \%$ experienced $1-5$ years, $15.5 \%$ experienced $5-10$ years, and $15.5 \%$ experienced more than 10 years.

Table 1. Middle- and old-aged homeless people demographic characteristics $(n=129)$.

\begin{tabular}{|c|c|c|}
\hline Variable & $n$ & $\%$ \\
\hline \multicolumn{3}{|l|}{ Gender } \\
\hline Males & 114 & 88.4 \\
\hline Females & 15 & 11.6 \\
\hline Age, mean \pm SD (range) & \multicolumn{2}{|c|}{$58.3 \pm 7.5(45.0-83.2)$} \\
\hline $45-54$ years & 34 & 26.4 \\
\hline 55-64 years & 66 & 51.2 \\
\hline$\geqq 65$ years & 29 & 22.5 \\
\hline \multicolumn{3}{|l|}{ Level of education } \\
\hline Elementary or less & 36 & 27.9 \\
\hline Junior High School & 39 & 30.2 \\
\hline Senior High School & 43 & 33.3 \\
\hline College and above & 11 & 8.6 \\
\hline \multicolumn{3}{|l|}{ Marital Status } \\
\hline Single & 66 & 51.2 \\
\hline Married & 6 & 4.7 \\
\hline Divorced & 47 & 36.4 \\
\hline Others & 10 & 7.7 \\
\hline \multicolumn{3}{|l|}{ Current living location } \\
\hline Convenience store surrounding & 1 & 0.8 \\
\hline Public Park & 53 & 41.1 \\
\hline Main station surrounding & 18 & 14.0 \\
\hline Homeless shelter & 37 & 28.7 \\
\hline Others & 20 & 15.4 \\
\hline \multicolumn{3}{|l|}{ Original household location } \\
\hline Taipei city & 68 & 52.7 \\
\hline New Taipei city & 41 & 31.8 \\
\hline Other cities & 20 & 15.5 \\
\hline \multicolumn{3}{|l|}{ Time of Living in the Street } \\
\hline$\leqq 1$ year & 36 & 27.9 \\
\hline $1-5$ years & 53 & 41.1 \\
\hline $5-10$ years & 20 & 15.5 \\
\hline
\end{tabular}


Table 1. Cont.

\begin{tabular}{ccc}
\hline Variable & $\boldsymbol{n}$ & $\mathbf{\%}$ \\
\hline$\geqq 10$ years & 20 & 15.5 \\
Smoking status & & \\
Never & 46 & 35.7 \\
Ever & 83 & 64.3 \\
Drinking status & 101 & 78.3 \\
Never & 28 & 21.7 \\
Ever & & \\
Chewing betel nut status & 103 & 79.8 \\
Never & 26 & 20.2 \\
Ever & &
\end{tabular}

With respect to enabling factors of the respondents (Table 2), $41.4 \%$ expressed that they were unemployed, $14 \%$ had a full-time job, and $44.9 \%$ of respondents reported that they had a part-time job. Their income sources included job payment (55.1\%), disability allowance (11.6), low-income subsidy $(3.1 \%)$, and other sources, which included family support, charity, and money loan. Nearly $30 \%$ of the respondents reported that they had no income at all, $6 \%$ got less than 3000 NT\$ monthly, 32.6\% got 3001-6000 NT\$, and only 13.9\% respondents expressed that they got more than ten-thousand NT\$ monthly.

Table 2. The distribution of enabling and need conditions in middle- and old-aged homeless people $(n=129)$.

\begin{tabular}{|c|c|}
\hline Variables & $n(\%)$ \\
\hline \multicolumn{2}{|l|}{ Employment status } \\
\hline None & $53(41.1)$ \\
\hline Full-time job & $18(14.0)$ \\
\hline Part time & $58(44.9)$ \\
\hline \multicolumn{2}{|l|}{ Economic Source } \\
\hline Earning income & $71(55.1)$ \\
\hline Subsidy for low income & $4(3.1)$ \\
\hline Allowance for the disabled & $15(11.6)$ \\
\hline Other & $39(30.2)$ \\
\hline \multicolumn{2}{|c|}{ Current income per month (NT dollars) } \\
\hline None & $38(29.5)$ \\
\hline Less than 3000 dollars & 15 (11.6) \\
\hline 3001-6000 dollars & $42(32.6)$ \\
\hline 6001-9000 dollars & $7(5.4)$ \\
\hline 9001-10,000 dollars & $9(7.0)$ \\
\hline More than 10,000 dollars & $18(13.9)$ \\
\hline \multicolumn{2}{|l|}{ National health insurance coverage } \\
\hline No & $6(4.7)$ \\
\hline Yes & $123(95.3)$ \\
\hline \multicolumn{2}{|l|}{ Usual healthcare setting } \\
\hline No & $27(20.9)$ \\
\hline Yes & $102(79.1)$ \\
\hline \multicolumn{2}{|l|}{ Usual healthcare physician } \\
\hline No & $59(45.7)$ \\
\hline Yes & $70(54.3)$ \\
\hline \multicolumn{2}{|l|}{ Transportation to clinic visit } \\
\hline By walking & $31(24.0)$ \\
\hline By bus & 46 (35.7) \\
\hline By MRT & $17(13.2)$ \\
\hline By motorcycle & $8(6.2)$ \\
\hline By bicycle & $12(9.3)$ \\
\hline
\end{tabular}


Table 2. Cont.

\begin{tabular}{cc}
\hline Variables & $\boldsymbol{n} \mathbf{( \% )}$ \\
\hline Other & $5(3.9)$ \\
Never visit in one year & $10(7.7)$ \\
Time spent on clinic visits & $92(71.3)$ \\
Less than one hour & $27(20.9)$ \\
More than one hour & $10(7.8)$ \\
Never visit in one year & \\
Psychiatric outpatient care & $80(62 \%)$ \\
Never & $49(38 \%)$ \\
Ever & $110(85.3 \%)$ \\
Psychiatric inpatient care & $19(14.7 \%)$ \\
Never & Ever
\end{tabular}

The need factors of the respondents are shown in Table 2. Their negative health behaviors showed that $64.3 \%$ were smokers, $20.2 \%$ have habits of chewing betel nut, and $21.7 \%$ often drink alcohol. The National Health Insurance coverage rate was high (95.3\%) in people experiencing homelessness, and $79.1 \%$ respondents reported that they have usual healthcare settings, and $54.3 \%$ respondents accepted healthcare by usual physicians. Regarding healthcare accessibility, approaching healthcare setting by bus (35.7\%), walking (24\%), and by mass-rapid transit (MRT) $(13.2 \%)$ were the most commonly used means among the respondents. Most of the respondents (71.3\%) were able to complete their healthcare visits in one hour, and $20.9 \%$ finished in two hours time. However, $7.8 \%$ of cases reported that they had not used any healthcare service in the last year.

\subsection{Distribution of Depressive Symptoms (PHQ-9 Scores)}

Table 3 presents the depressive conditions among middle-and old-aged homeless people. The results showed that $15.5 \%$ respondents were free of depression, $16.3 \%$ had mild level (score $5-9$ ), 31.8\% had moderate depression (score 10-14), 26.4\% had moderately severe depression (score 15-19), and $10.1 \%$ had severe depression (score 20-27). Adopting a PHQ-9 score 10 as a cut-off point for major depressive symptoms, $68.3 \%$ of middle-aged and older homeless adults were the cases needing to be referred to healthcare settings, for further diagnoses and treatments of their depressive conditions.

Table 3. Depressive symptoms among middle- and old-aged homeless people.

\begin{tabular}{ccc}
\hline Depressive Conditions & $\boldsymbol{n ( \% )}$ & Mean \pm SD \\
\hline Depression severity $^{\mathrm{a}}$ & & $12.1 \pm 6.5$ \\
No & $20(15.5)$ & \\
Mild & $21(16.3)$ & \\
Moderate & $41(31.8)$ & \\
Moderately severe & $34(26.4)$ & \\
Severe $_{\text {Major depressive symptom }}{ }^{\mathrm{b}}$ & $13(10.1)$ & \\
No & $41(31.8)$ & \\
Yes & $88(68.2)$ & \\
\hline
\end{tabular}

a Depression severity category (PHQ-9 score): no (0-4), mild (5-9), moderate (10-14), moderately severe (15-19), severe (20-27); ${ }^{\mathrm{b}}$ Cut-off point of major depressive symptom: yes (PHQ-9 score $\geqq 10$ ), no (PHQ-9 score $<10$ ).

\subsection{Correlates of Depressive Symptoms in Homeless Adults}

Table 4 shows presents univariate chi-square analyses of the relation between participant's characteristics and major depressive symptoms (PHQ-9 cutoff point: 10). The results showed that factors of age $(p=0.03)$, gender $(p=0.05)$, and used psychiatric outpatient care $(p=0.01)$ statistically related to the presence of major depressive symptoms, while the other factors did not indicate significant 
correlation. Finally, the significant factors in univariate tests were put in multiple logistic regression analyses, to identify the associated factors with the occurrence of major depressive symptoms in the participants (Table 5). The results revealed that gender, age, and usage of psychiatric outpatient care were associated with major depressive symptom occurrence. The female participants were less likely to have major depressive symptoms than the male participants ( $\mathrm{OR}=0.29,95 \% \mathrm{CI}=0.09-0.96)$. The elderly participants were more likely to have major depressive symptoms than the aged $45-54$ years $(\mathrm{OR}=5.29,95 \% \mathrm{CI}=1.44-19.41)$. Those participants having ever used psychiatric outpatient care were significantly more correlated with the occurrence of major depressive symptoms than their counterparts $(\mathrm{OR}=3.65,95 \% \mathrm{CI}=1.46-9.09)$.

Table 4. Relation of homeless people characteristics and major depressive symptoms (chi-square test).

\begin{tabular}{|c|c|c|c|c|}
\hline \multirow{2}{*}{ Variables } & \multicolumn{3}{|c|}{ Major Depressive Symptom $^{\text {a }}$} & \multirow{2}{*}{$p$ Value } \\
\hline & Yes; $n(\%)$ & No; $n(\%)$ & Total; $n(\%)$ & \\
\hline Gender & & & & 0.05 \\
\hline Males & $81(71.1)$ & $33(28.9)$ & $114(88.4)$ & \\
\hline Females & $7(46.7)$ & $8(53.3)$ & $15(11.6)$ & \\
\hline Age & & & & 0.03 \\
\hline $45-54$ years & 19 (55.9) & $15(44.1)$ & $34(26.3)$ & \\
\hline 55-64 years & $44(66.7)$ & $22(33.3)$ & $66(51.2)$ & \\
\hline$\geqq 65$ years & $25(86.2)$ & $4(13.8)$ & $29(22.5)$ & \\
\hline Education level & & & & 0.42 \\
\hline Elementary or less & $28(77.8)$ & $8(22.2)$ & $36(27.9)$ & \\
\hline Junior High School & $27(69.2)$ & $12(30.8)$ & $39(30.2)$ & \\
\hline Senior High School & $26(60.5)$ & $17(39.5)$ & $43(33.4)$ & \\
\hline College and above & $7(63.6)$ & $4(36.4)$ & $11(8.5)$ & \\
\hline Marital status & & & & 0.29 \\
\hline Single & $44(66.7)$ & $22(33.3)$ & $66(51.1)$ & \\
\hline Married & $2(33.3)$ & $4(66.7)$ & $6(4.7)$ & \\
\hline Divorced & $35(74.5)$ & $12(25.5)$ & $47(36.4)$ & \\
\hline Others & $7(70.0)$ & $3(30.0)$ & $10(7.8)$ & \\
\hline Current living location & & & & 0.64 \\
\hline Convenience store & $1(100)$ & 0 & $1(0.8)$ & \\
\hline Public park & $39(73.6)$ & $14(26.4)$ & $53(41.1)$ & \\
\hline Main station & $11(61.1)$ & $7(38.9)$ & $18(14.0)$ & \\
\hline Homeless shelter & $23(62.2)$ & $14(37.8)$ & $37(28.6)$ & \\
\hline Others & $14(70.0)$ & $6(30.0)$ & $20(15.5)$ & \\
\hline $\begin{array}{l}\text { Original household } \\
\text { location }\end{array}$ & & & & 0.92 \\
\hline Taipei city & $47(69.1)$ & $21(30.9)$ & $68(52.7)$ & \\
\hline New Taipei city & $27(65.9)$ & $14(34.1)$ & $41(31.8)$ & \\
\hline Other city & $14(70.0)$ & $6(30.0)$ & $20(15.5)$ & \\
\hline Time of living in the street & & & & 0.39 \\
\hline Less than one year & $21(58.3)$ & $15(41.7)$ & $36(27.9)$ & \\
\hline $1-5$ year & $40(75.5)$ & $13(24.5)$ & $53(41.1)$ & \\
\hline 5-10 year & $13(65.0)$ & $7(35.0)$ & $20(15.5)$ & \\
\hline More than ten years & $14(70.0)$ & $6(30.0)$ & $20(15.5)$ & \\
\hline Smoking status & & & & 0.81 \\
\hline Never & $32(69.6)$ & $14(30.4)$ & $46(35.7)$ & \\
\hline Ever & $56(67.5)$ & $27(32.5)$ & $83(64.3)$ & \\
\hline Drinking status & & & & 0.61 \\
\hline Never & $70(69.3)$ & $31(30.7)$ & $101(78.3)$ & \\
\hline Ever & $18(64.3)$ & $10(35.7)$ & $28(21.7)$ & \\
\hline Chewing betel nut status & & & & 0.55 \\
\hline Never & $69(67.0)$ & $34(33.0)$ & $103(79.8)$ & \\
\hline Ever & $19(73.1)$ & $7(26.9)$ & $26(20.2)$ & \\
\hline Psychiatric outpatient care & & & & 0.01 \\
\hline Never & $48(60.0)$ & $32(40.0)$ & $80(62.0)$ & \\
\hline
\end{tabular}


Table 4. Cont.

\begin{tabular}{ccccc}
\hline \multirow{2}{*}{ Variables } & \multicolumn{3}{c}{ Major Depressive Symptom a } & \multirow{2}{*}{ Yalue } \\
& Yes; $\boldsymbol{n} \mathbf{( \% )}$ & No; $\boldsymbol{n} \mathbf{( \% )}$ & Total; $\boldsymbol{n} \mathbf{( \% )}$ & \multirow{2}{*}{ Value } \\
\hline Ever & $40(81.6)$ & $9(18.4)$ & $49(38.0)$ & \multirow{2}{*}{0.11} \\
$\begin{array}{c}\text { Psychiatric inpatient care } \\
\text { Never }\end{array}$ & $72(65.5)$ & $38(34.5)$ & $110(85.3)$ & \\
Ever & $16(84.2)$ & $3(15.8)$ & $19(14.7)$ & \\
\hline
\end{tabular}

Table 5. Logistic regression analysis of major depressive symptom occurrence $(n=129)$.

\begin{tabular}{ccc}
\hline Variables & OR $\mathbf{( 9 5} \% \mathbf{C I})$ & $p$ Value \\
\hline Gender & & \\
Males & Reference & 0.04 \\
Females & $0.29(0.09-0.96)$ & \\
Age & & \\
45-54 years & Reference & 0.46 \\
$55-64$ years & $1.40(0.58-3.43)$ & 0.01 \\
$\geqq 65$ years & $5.29(1.44-19.41)$ & \\
Psychiatric outpatient care & Reference & $<0.01$ \\
Never & $3.65(1.46-9.09)$ & \\
Ever & &
\end{tabular}

\section{Discussion}

Homelessness aggravates already poor health, as well as susceptibility to worsening health issues such as pneumonia, depression, dementia, and more. The consequence for older homeless people who live on the streets is that they are much more likely to become victims of violent crime because of their weak health and mobility [50]. Older homeless adults are more at risk of developing chronic and debilitating diseases such as diabetes, heart and related respiratory diseases, and others as a result of premature aging [51]. A survey of Oakland's older homeless, in California, has shown that a large proportion of the older homeless population first became homeless later in life, and once they became homeless, their health declined precipitously [18]. Therefore, specialized healthcare services for the homeless were developed when it became clear that the mainstream healthcare system could not sufficiently address their health needs [52], particularly in the middle-aged and older homeless population whose prevalent chronic diseases meant they needed to make repeated visits to their healthcare provider and adhere to complicated medication regimens, specific diets, and physical routines [53]. The present study was one of the first studies to screen for depressive symptoms and correlates among middle-aged and older homeless adults based on the PHQ-9 tool, to provide information to further the mental health initiative for this group of people.

The cut-off points of PHQ-9 score of 10 has been found to be good in sensitivity and specificity for a screening of major depressive symptoms in primary care settings [32]. Based on this criterion, our results indicated that $68.3 \%$ of homeless adults were screened as potential cases (moderate to severe level of depression) and required further diagnosis to identify and follow up their depressive conditions. Compared to other studies, $80 \%$ of homeless people reported that they had mental health problems, with $45 \%$ having been diagnosed in England [54]. In the USA, approximately 30\% of people who are chronically homeless have mental health conditions, over $60 \%$ have experienced lifetime mental health problems [55], and nearly half of homeless women meet major depressive disorder criteria, which is double the prevalence in women in general [56]. In Hong Kong, Yim et al. [57] found that the point prevalence of mental illness was $56 \%$ in homeless people, and $71 \%$ of cases experienced a lifetime history of mental illness. However, quantifying the problems of mental illness among homeless populations is difficult, and estimates have varied considerably according to different approaches [58]. The present study used PHQ-9 scores $\geq 10$ to estimate major depression prevalence; however, PHQ-9 
$\geq 10$ may substantially overestimate depressive condition, and there are too many confounding factors needed to control statistically. It has been suggested that the estimation of depression prevalence should be based on further specialist diagnoses to determine cases correctly [59].

Service providers suggested that homelessness among older adults has notably increased, and more awareness and training is needed for members of the public and service providers on psycho-geriatric and health issues/services [19]. Those middle-aged and older homeless who had been continuously homeless have a higher prevalence of disabling conditions and health needs [20,60]. To prevent the middle-aged and older adults from becoming homeless, we should diminish the risk factors of homelessness and health disparities. Homeless individuals are at high risk of poor health and mental illnesses, previous studies disclosing that they tend to be more psychologically distressed than others [61-64], particularly in depression, addiction disorder, anxiety, schizophrenia, and bipolar disorder [15]. An Australian study [65] found that 31\% of homeless people experienced a mental health problem, and nearly half had a mental health problem prior to becoming homeless. In addition, older homeless adults appeared to follow a different treatment trajectory than younger counterparts, possibly because of lower severity of mental illness at baseline, and may need specific interventions to address their unique pathways to homelessness [66].

The participants' health behaviors showed that $64.3 \%$ were smokers, $20.2 \%$ have habits of chewing betel nut, and $21.7 \%$ often drink alcohol. This population has many physical and mental health problems, and use of drugs, alcohol, and smoking is common, and co-morbidity is common, with a study reporting they have 5.3 ill health conditions per person [15]. In a profile analysis of the health behaviors of homeless people in South Africa, researchers found that homeless patients reported consuming alcohol (32\%), smoking cigarettes (33\%), and/or using recreational drugs (7\%) [67]. As co-morbidity is common among homeless people, to strengthen accessible and available primary healthcare will be a pre-requisite for improving effective health interventions [68], particularly, to enable homeless people to have access to the range of services that already exist, thereby decreasing their need for specialized services, to protect and improve their health [69].

Regarding healthcare accessibility, homeless people face many service disparities, such as a lack of service co-ordination and health insurance as major barriers in service provision [70]. However, the national health insurance coverage is high, and homeless adults can access healthcare facilities easily in Taiwan, and $79.1 \%$ of respondents reported that they have usual healthcare settings, and $54.3 \%$ of respondents accepted healthcare by usual physicians. Compared to other studies, $57 \%$ of the subjects reported that they had a regular source of care and that the barrier factors included male gender, Hispanic ethnicity, and younger age [71]. Depression severity level was significantly associated with medical utilization in homeless individuals [10]. In addition, homeless people with mental health diagnoses and substance abuse were likely to be higher users of healthcare compared to their counterparts [72]. Another study revealed that those homeless people with chronic mental illness and substance dependence were likely to have a regular source of care [71]. However, initiating coordinated treatment programs for homeless adults with mental illness usually results in better health outcomes than usual care [73]. Therefore, how to construct a suitable healthcare system for the older homeless adults is the further direction of health policy initiatives.

Management of mental illness and substance misuse problems were a challenge to society [12]. The present study found that $38 \%$ of respondents had used psychiatric clinic visits, and $14.7 \%$ used inpatient services; therefore, healthcare services for this vulnerable population require much more attention. A previous study found that homeless patients had increased rates of emergency care in alcohol and substance abuse and mental-health-related problems [74]. Koegel et al. [75] revealed that $22 \%$ of homeless adults met the criteria for chronic mental illness, and less than one-fifth of these cases reported receiving treatment within the last 2 months. Mental health service utilization was influenced by factors of health needs, such as diagnosis, awareness of a mental ill problem. Providing access to primary care physicians and other services in a community-based shelter program can assist in identification of mental illness and cognitive impairment in elderly homeless adults [76]. To improve 
psychiatric and homeless services, many crucial needs have to be addressed such as understanding these individuals and their lives; being more proactive in helping them; and reinventing long-term, structured, humane residential and inpatient settings [77].

Finally, a significant percentage of PHQ-9 issues appeared in the "nearly every day" category and required more attention among this group of people, such as "trouble sleeping", "feeling bad about yourself", "feeling tired or having little energy", "feeling down, depressed, or hopeless", "trouble concentrating on things", and "little interest or pleasure in doing things". The present study also reveals that older homeless adults are more likely to experience major depressive symptoms. In future health policy initiatives, as $\mathrm{O}^{\prime}$ Brien et al. [78] highlight, adopting patient-centered care and targeted interventions can increase primary care access and improve mental health among homeless people [79]. Furthermore, a multisectoral partnership approach, an integrated person-centered care, and initiating a public health system to monitor serious mental illness and health disparities will be beneficious for the homeless population [80].

The many limitations of this study include the cross-sectional design and self-report data lacking a cause-effect relationship, participant's privacy affecting health status and health behaviors, the recall bias of healthcare utilization, and the low response rate of the participants. Moreover, the PHQ-9 is a screening scale design, rather than a diagnostic tool for depressive symptoms. Therefore, the actual prevalence of depressive symptoms in homeless population is unclear.

\section{Conclusions}

To protect the health rights of homeless people, programs have been targeted to the homeless in general; specific programs have been targeted to certain subpopulations such as middle-aged and older adults that are represented by the nature of their health problems, demographic characteristics that necessitate specialized approaches [69]. The present study revealed that $68.3 \%$ of homeless adults were identified as major depressive symptom cases requiring follow-up, particularly in the older age of this population. We conclude that in the future health policy initiatives need to build patient-centered care and initiate effective interventions to improve care accessibility among the homeless [79]. Furthermore, adopting a multisectoral partnership approach to monitor serious mental illness and health disparities will be beneficious for the homeless population. Finally, the present study highlights that the health policy should eliminate the risk factors of depressive symptoms and improve mental healthcare access, to improve the health and wellbeing of the homeless population.

Author Contributions: Research design, J.-D.L.; draft writing and editing, L.-Y.W., L.-P.L., and J.-D.L.; data collection and administration, L.-Y.W.; statistical analysis, L.-Y.W., Y.-C.C., and T.-W.W. All authors have read and agreed to the published version of the manuscript.

Funding: The authors have not received financial support for this research and work.

Acknowledgments: We would like to thank the organizations of the Taipei Wanhua District Welfare Center and Homeless Taiwan who administratively supported this study and those homeless friends who participated in the study.

Conflicts of Interest: The authors declare no conflicts of interest.

\section{References}

1. Bax, A.; Middleton, J. Healthcare for people experiencing homelessness. BMJ 2019, 364, 11022. [CrossRef]

2. Blackburn, P. Streets of Shame. 2019. pp. 7-13. Available online: https://www.bma.org.uk/news/thedoctor (accessed on 20 April 2020).

3. Gelberg, L.; Andersen, R.M.; Leake, B.D. The Behavioral Model for Vulnerable Populations: Application to medical care use and outcomes for homeless people. Health Serv. Res. 2000, 34, 1273-1302.

4. Wadhera, R.K.; Choi, E.; Shen, C.; Yeh, R.W.; Joynt Maddox, K.E. Trends, causes, and outcomes of hospitalizations for homeless individuals: A retrospective cohort study. Med. Care 2019, 57, 21-27. [CrossRef] [PubMed] 
5. Wadhera, R.K.; Khatana, S.A.M.; Choi, E.; Jiang, G.; Shen, C.; Yeh, R.W.; Joynt Maddox, K.E. Disparities in care and mortality among homeless adults hospitalized for cardiovascular conditions. JAMA Intern. Med. 2019, 180, 357-366. [CrossRef] [PubMed]

6. Stafford, A.; Wood, L. Tackling health disparities for people who are homeless? Start with social determinants. Int. J. Environ. Res. Public Health 2017, 14, 1535. [CrossRef] [PubMed]

7. Gunner, E.; Chandan, S.K.; Marwick, S.; Saunders, K.; Burwood, S.; Yahyouche, A.; Paudyal, V. Provision and accessibility of primary healthcare services for people who are homeless: A qualitative study of patient perspectives in the UK. Br. J. Gen. Pract 2019, 69, e526-e536. [CrossRef]

8. Aizuddin, A.N.; Abdul Jabar, S.W.; Idris, I.B. Factors associated with health services financier among temporary sheltered homeless in urban Malaysia. BMC Public Health 2019, 19, S548. [CrossRef]

9. Hwang, S.W.; Burns, T. Health interventions for people who are homeless. Lancet 2014, 384, $1541-1547$. [CrossRef]

10. Yoon, C.; Ju, Y.S.; Kim, C.Y. Disparities in health care utilization among urban homeless in South Korea: A cross-sectional study. J. Prev. Med. Public Health 2011, 44, 267-274. [CrossRef]

11. Argintaru, N.; Chambers, C.; Gogosis, E.; Farrell, S.; Palepu, A.; Klodawsky, F.; Hwang, S.W. A cross-sectional observational study of unmet health needs among homeless and vulnerably housed adults in three Canadian cities. BMC Public Health 2013, 13, 577. [CrossRef]

12. Mc Conalogue, D.; Maunder, N.; Areington, A.; Martin, K.; Clarke, V.; Scott, S. Homeless people and health: A qualitative enquiry into their practices and perceptions. J. Public Health 2019. [CrossRef] [PubMed]

13. Cantor, J.C.; Chakravarty, S.; Nova, J.; Kelly, T.; Delia, D.; Tiderington, E.; Brown, R.W. Medicaid utilization and spending among homeless adults in New Jersey: Implications for Medicaid-funded tenancy support services. Milbank Q. 2020, 98, 106-130. [CrossRef]

14. O'Carroll, A.; Wainwright, D. Making sense of street chaos: An ethnographic exploration of homeless people's health service utilization. Int. J. Equity Health 2019, 18, 113. [CrossRef] [PubMed]

15. Keogh, C.; O’Brien, K.K.; Hoban, A.; O'Carroll, A.; Fahey, T. Health and use of health services of people who are homeless and at risk of homelessness who receive free primary health care in Dublin. BMC Health Serv. Res. 2015, 15, 58. [CrossRef] [PubMed]

16. Scott, J. Homelessness and mental illness. Br. J. Psychiatry 1993, 162, 314-324. [CrossRef]

17. Culhane, D.P.; Metraux, S.; Byrne, T.; Stino, M.; Bainbridge, J. The age structure of contemporary homelessness: Evidence and implications for public policy. Anal. Soc. Issues Public Policy 2013, 13, 228-244. [CrossRef]

18. Brown, R.T.; Goodman, L.; Guzman, D.; Tieu, L.; Ponath, C.; Kushel, M.B. Pathways to homelessness among older homeless adults: Results from the HOPE HOME study. PLoS ONE 2016, 11, e0155065. [CrossRef]

19. McDonald, L.; Dergal, J.; Cleghorn, L. Homeless Older Adults Research Project Executive Summary; Institute for Human Development, Life Course and Aging, University of Toronto: Toronto, ON, Canada, 2004.

20. Brown, R.T.; Kiely, D.K.; Bharel, M.; Mitchell, S.L. Geriatric syndromes in older homeless adults. J. Gen. Intern. Med. 2012, 27, 16-22. [CrossRef]

21. Cohen, C.I. Aging and homelessness. Gerontologist 1999, 39, 5-14. [CrossRef] [PubMed]

22. Hahn, J.A.; Kushel, M.B.; Bangsberg, D.R.; Riley, E.; Moss, A.R. The aging of the homeless population: Fourteen-year trends in San Francisco. J. Gen. Intern. Med. 2006, 21, 775-778. [CrossRef]

23. Yamane, D.P.; Oeser, S.G.; Omori, J. Health disparities in the Native Hawaiian homeless. Hawaii Med. J. 2010, 69, 35-41. [PubMed]

24. Gonyea, J.G.; Mills-Dick, K.; Bachman, S.S. The complexities of elder homelessness, a shifting political landscape and emerging community responses. J. Gerontol. Soc. Work. 2010, 53, 575-590. [CrossRef] [PubMed]

25. Cheng, L.C.; Yang, Y.S. Homeless problems in Taiwan: Looking beyond legality toward social issues. City Cult. Soc. 2010, 3, 165-173. [CrossRef]

26. The Salvation Army. Taipei Homeless Caring Center. Available online: https://en.salvationarmy.org.tw/ taipei-homeless-caring-centre.html (accessed on 19 June 2020).

27. Kim, J. Homelessness Was (and Still Is) Taboo in Taipei City. The China Post. 30 July 2018. Available online: https://chinapost.nownews.com/20180730-388776 (accessed on 19 June 2020).

28. Pan, S.M. Genealogy and ideology of Taiwan homeless delivery services. J. Soc. Distress Homeless 2010, 15, 253-272. [CrossRef] 
29. Vandentorren, S.; Chauvin, P. Health and health care for homeless people in various contexts. Int. J. Environ. Res. Public Health 2018, 15, 948. [CrossRef]

30. Ministry of the Interiors. Handled Conditions of Homeless People. 2017. Available online: https: //dep.mohw.gov.tw/DOS/cp-2973-13796-113.html (accessed on 14 April 2020).

31. Kroenke, K.; Spitzer, R.L. The PHQ-9: A new depression diagnostic and severity measure. Psychiatr. Ann. 2002, 32, 509-515. [CrossRef]

32. Spitzer, R.L.; Kroenke, K.; Williams, J.B. Validation and utility of a self-report version of PRIME-MD: The PHQ primary care study. Primary Care Evaluation of Mental Disorders. Patient Health Questionnaire. JAMA 1999, 282, 1737-1744. [CrossRef]

33. Spitzer, R.L.; Williams, J.B.; Kroenke, K.; Hornyak, R.; McMurray, J. Validity and utility of the PRIME-MD patient health questionnaire in assessment of 3000 obstetric-gynecologic patients: The PRIME-MD Patient Health Questionnaire Obstetrics-Gynecology Study. Am. J. Obstet. Gynecol. 2000, 183, 759-769. [CrossRef]

34. Acer, A.M. Detecting and managing depressing in type II: PHQ-9 is the answer. Medsurg. Nursing 2010, 19, 32-38.

35. Chen, T.M.; Huang, F.Y.; Chang, C.; Chung, H. Using the PHQ-9 for depression screening and treatment monitoring for Chinese Americans in primary care. Psychiatr. Serv. 2006, 57, 976-981. [CrossRef]

36. Dbouk, N.; Arguedas, M.R.; Sheikh, A. Assessment of the PHQ-9 as a screening tool for depression in patients with chronic hepatitis C. Dig. Dis. Sci. 2008, 53, 1100-1106. [CrossRef]

37. De Lima Osório, F.; Vilela Mendes, A.; Crippa, J.A.; Loureiro, S.R. Study of the discriminative validity of the PHQ-9 and PHQ-2 in a sample of Brazilian women in the context of primary health care. Perspect Psychiatr. Care 2009, 45, 216-227. [CrossRef] [PubMed]

38. Lloyd, C.E.; Roy, T.; Begum, S.; Mughal, S.; Barnett, A.H. Measuring psychological well-being in South Asians with diabetes; a qualitative investigation of the PHQ-9 and the WHO-5 as potential screening tools for measuring symptoms of depression. Diabet. Med. 2012, 29, 140-147. [CrossRef] [PubMed]

39. Milette, K.; Hudson, M.; Baron, M.; Thombs, B.D. Canadian Scleroderma Research Group. Comparison of the PHQ-9 and CES-D depression scales in systemic sclerosis: Internal consistency reliability, convergent validity and clinical correlates. Rheumatology 2010, 49, 789-796. [CrossRef] [PubMed]

40. Richardson, E.J.; Richards, J.S. Factor structure of the PHQ-9 screen for depression across time since injury among persons with spinal cord injury. Rehabil. Psychol. 2008, 53, 243-249. [CrossRef]

41. Sjonnesen, K.; Berzins, S.; Fiest, K.M.; Bulloch, A.G.; Metz, L.M.; Thombs, B.D.; Patter, S.B. Evaluation of the 9-item Patient Health Questionnaire (PHQ-9) as an assessment instrument for symptoms of depression in patients with multiple sclerosis. Postgrad Med. 2012, 124, 69-77. [CrossRef]

42. Yawn, B.P.; Pace, W.; Wollan, P.C.; Bertram, S.; Kurland, M.; Graham, D.; Dietrich, A. Concordance of Edinburgh Postnatal Depression Scale (EPDS) and Patient Health Questionnaire (PHQ-9) to assess increased risk of depression among postpartum women. J. Am. Board Fam Med. 2009, 22, 483-491. [CrossRef]

43. Yu, X.; Tam, W.W.; Wong, P.T.; Lam, T.H.; Stewart, S.M. The Patient Health Questionnaire-9 for measuring depressive symptoms among the general population in Hong Kong. Compr. Psychiatry 2012, 53, 95-102. [CrossRef] [PubMed]

44. Wang, W.; Bian, Q.; Zhao, Y.; Li, X.; Wang, W.; Du, J.; Zhang, G.; Zhou, Q.; Zhao, M. Reliability and validity of the Chinese Version of the Patient Health Questionnaire (PHQ-9) in the General Population. Gen. Hosp. Psychiatry 2014, 36, 539-544. [CrossRef]

45. Zhang, Y.L.; Liang, W.; Chen, Z.M.; Zhang, H.M.; Zhang, J.H.; Weng, X.Q.; Yang, S.C.; Zhang, L.; Shen, L.J.; Zhang, Y.L. Validity and reliability of Patient Health Questionnaire-9 and Patient Health Questionnaire-2 to screen for depression among college students in China. Asia Pac. Psychiatry 2013, 5, 268-275. [CrossRef]

46. Xia, N.G.; Lin, J.H.; Ding, S.Q.; Dong, F.R.; Shen, J.Z.; Du, Y.R.; Wang, X.S.; Chen, Y.Y.; Zhu, Z.G.; Zheng, R.Y.; et al. Reliability and validity of the Chinese Version of the Patient Health Questionnaire 9 (C-PHQ-9) in patients with epilepsy. Epilepsy Behav. 2019, 95, 65-69. [CrossRef] [PubMed]

47. Tsai, F.J.; Huang, Y.H.; Liu, H.C.; Huang, K.Y.; Huang, Y.H.; Liu, S.I. Patient Health Questionnaire for school-based depression screening among Chinese adolescents. Pediatrics 2014, 133, e402-e409. [CrossRef] [PubMed]

48. Peng, T.; Li, Z.M.; Liu, J.; Zhang, Y. Evaluation of reliability and validity of the Patient Health Questionnaire-9 in patients with acne. Dermatol. Ther. 2020, 14, e13584. 
49. Kroenke, K.; Spitzer, R.L.; Williams, J.B.W. The PHQ-9: Validity of a brief depression severity measure. J. Gen. Intern. Med. 2001, 16, 606-613. [CrossRef] [PubMed]

50. The City Mission, Cleveland, $\mathrm{OH}$. Aging into Homelessness: A Growing Crisis. Available online: https: //www.thecitymission.org/blog/older-homeless/ (accessed on 19 June 2020).

51. Sorrell, J.M. Aging on the street: Homeless older adults in America. J. Psychosoc. Nurs. Ment. Health Serv. 2016, 54, 25-29. [CrossRef] [PubMed]

52. Zlotnick, C.; Zerger, S.; Wolfe, P.B. Health care for the homeless: What we have learned in the past 30 years and what's next. Am. J. Public Health 2013, 103, S199-S205. [CrossRef]

53. The Conversation. How the Homeless Population Is Changing: It's Older and Sicker. Available online: https: //theconversation.com/how-the-homeless-population-is-changing-its-older-and-sicker-50632 (accessed on 19 June 2020).

54. Homeless Link. The Unhealthy State of Homelessness: Health Audit Results 2014. Available online: homeless.org.uk/sites/default/files/site-attachments/The $\% 20$ unhealthy\%20state\%20of $\%$ 20homelessness\%20FINAL.pdf (accessed on 30 April 2020).

55. Caton, C.L.; Dominguez, B.; Schanzer, B.; Hasin, D.S.; Shrout, P.E.; Felix, A.; McQuistion, H.; Opler, L.A.; Hsu, E. Risk factors for long-term homelessness: Findings from a longitudinal review of first-time homeless single adults. Am. J. Public Health. 2005, 95, 1753-1759. [CrossRef]

56. Bassuk, E.L.; Beardslee, W.R. Depression in homeless mothers: Addressing an unrecognized public health issue. Am. J. Orthopsychiatry 2014, 84, 73-81. [CrossRef]

57. Yim, L.C.L.; Leung, H.C.M.; Chan, W.C.; Lam, M.H.B.; Lim, V.W.M. Prevalence of Mental Illness among Homeless People in Hong Kong. PLoS ONE 2015, 10, e0140940. [CrossRef]

58. Australian Government Department of Health. National Mental Health Report 2013. Indicator 19: Prevalence of Mental Illness among Homeless Populations. Available online: https://www1.health.gov.au/internet/publications/publishing.nsf/Content/mental-pubs-n-report13toc $\sim\{\}$ mental-pubs-n-report13-3 \{\}mental-pubs-n-report13-3-4 \{\}mental-pubs-n-report13-3-4-ind19 (accessed on 30 April 2020).

59. Levis, B.; Benedetti, A.; Ioannidis, J.P.A.; Sun, Y.; Negeri, A.; He, C.; Wu, Y.; Krishnan, A.; Bhandari, P.M.; Neupane, D.; et al. Patient Health Questionnaire-9 scores do not accurately estimate depression prevalence: Individual participant data meta-analysis. J. Clin. Epidemiol. 2020, 122, 115-128. [CrossRef]

60. Gelberg, L.; Linn, L.S.; Mayer-Oakes, S.A. Differences in health status between older and younger homeless adults. J. Am. Geriatr. Soc. 1990, 38, 1220-1229. [CrossRef] [PubMed]

61. Goering, P.; Tolomiczenko, G.; Sheldon, T.; Boydell, K.; Wasylenki, D. Characteristics of persons who are homeless for the first time. Psychiatr. Serv. 2002, 53, 1472-1474. [CrossRef] [PubMed]

62. Unger, J.B.; Kipke, M.D.; Simon, T.R.; Montgomery, S.B.; Johnson, C.J. Homeless youths and young adults in Los Angeles: Prevalence of mental health problems and the relationship between mental health and substance abuse disorders. Am. J. Community Psychol. 1997, 25, 371-382. [CrossRef] [PubMed]

63. Susser, E.; Struening, E.L.; Conover, S. Psychiatric problems in homeless men. Lifetime psychosis, substance use, and current distress in new arrivals at New York City shelters. Arch. Gen. Psychiatry 1989, 46, 845-850.

64. Berg, J.; Nyamathi1, A.; Christiani, A.; Morisky, D.; Leake, B. Predictors of screening results for depressive symptoms among homeless adults in Los Angeles with latent tuberculosis. Res. Nurs. Health 2005, 28, 220-229. [CrossRef]

65. Australian Institute of Health and Welfare. Australia's Welfare 2011. Canberra: Australian Institute of Health and Welfare. Available online: https://www.aihw.gov.au/getmedia/658dc9a1-6e55-4161-b26f-bcd45c014ff6/ 12927.pdf.aspx?inline=true (accessed on 20 April 2020).

66. Gordon, R.J.; Rosenheck, R.A.; Zweig, R.A.; Harpaz-Rotem, I. Health and social adjustment of homeless older adults with a mental illness. Psychiatr Serv. 2012, 63, 561-568. [CrossRef]

67. Johnston, D.; McInerney, P.; Miot, J. A profile of the health of homeless at an inner city primary health care clinic in South Africa. J. Health Care Poor Underserved 2019, 30, 1455-1466. [CrossRef]

68. Wright, N.M.; Tompkins, C.N. How can health services effectively meet the health needs of homeless people? Br. J. Gen. Pract. 2006, 56, 286-293.

69. Institute of Medicine (US) Committee on Health Care for Homeless People. Homelessness, Health, and Human Needs; National Academies Press: Washington, DC, USA, 1988. 
70. Canavan, R.; Barry, M.M.; Matanov, A.; Barros, H.; Gabor, E.; Greacen, T.; Holcnerová, P.; Kluge, U.; Nicaise, P.; Moskalewicz, J.; et al. Service provision and barriers to care for homeless people with mental health problems across 14 European capital cities. BMC Health Serv. Res. 2012, 12, 222. [CrossRef]

71. Gallagher, T.C.; Andersen, R.M.; Koegel, P.; Gelberg, L. Determinants of regular source of care among homeless adults in Los Angeles. Med. Care 1997, 35, 814-830. [CrossRef]

72. Zhang, L.; Norena, M.; Gadermann, A.; Hubley, A.; Russell, L.; Aubry, T.; To, M.J.; Farrell, S.; Hwang, S.; Palepu, A. Concurrent disorders and health care utilization among homeless and vulnerably housed persons in Canada. J. Dual Diagn. 2018, 14, 21-31. [CrossRef] [PubMed]

73. Hwang, S.W.; Tolomiczenko, G.; Kouyoumdjian, F.G.; Garner, R.E. Interventions to improve the health of the homeless: A systematic review. Am. J. Prev. Med. 2005, 29, 311-319. [CrossRef] [PubMed]

74. Lombardi, K.; Pines, J.M.; Mazer-Amirshahi, M.; Pourmand, A. Findings of a national dataset analysis on the visits of homeless patients to US emergency departments during 2005-2015. Public Health 2020, 178, 82-89. [CrossRef] [PubMed]

75. Koegel, P.; Sullivan, G.; Burnam, A.; Morton, S.C.; Wenzel, S. Utilization of mental health and substance abuse services among homeless adults in Los Angeles. Med. Care 1999, 37, 306-317. [CrossRef] [PubMed]

76. Joyce, D.P.; Limbos, M. Identification of cognitive impairment and mental illness in elderly homeless men: Before and after access to primary health care. Can. Fam. Physician 2009, 55, 1110-1111.

77. Glick, I.D.; Olfson, M. Psychiatric services and "the homeless": Changing the paradigm. J. Nerv. Ment. Dis. 2018, 206, 378-379. [CrossRef]

78. O’Brien, K.K.; Schuttke, A.; Alhakeem, A.; Donnelly-Swift, E.; Keogh, C.; O'Carroll, A.; O'Sullivan, K.; Galvin, R.; Fahey, T. Health, perceived quality of life and health services use among homeless illicit drug users. Drug Alcohol Depend. 2015, 154, 139-145. [CrossRef]

79. White, B.M.; Newman, S.D. Access to primary care services among the homeless: A synthesis of the literature using the equity of access to medical care framework. J. Prim. Care Community Health 2015, 6, 77-87. [CrossRef]

80. Weinstein, L.C.; Lanoue, M.D.; Plumb, J.D.; King, H.; Stein, B.; Tsemberis, S. A primary care-public health partnership addressing homelessness, serious mental illness, and health disparities. J. Am. Board Fam. Med. 2013, 26, 279-287. [CrossRef]

(C) 2020 by the authors. Licensee MDPI, Basel, Switzerland. This article is an open access article distributed under the terms and conditions of the Creative Commons Attribution (CC BY) license (http://creativecommons.org/licenses/by/4.0/). 